Article

\title{
Quantifying the Impacts of Systemic Acquired Resistance to Pitch Canker on Monterey Pine Growth Rate and Hyperspectral Reflectance
}

\author{
Gregory J. Reynolds ${ }^{1}$, Thomas R. Gordon ${ }^{2, *}$ and Neil McRoberts ${ }^{2}$ \\ Received: 1 October 2015; Accepted: 31 December 2015; Published: 12 January 2016 \\ Academic Editors: Jan Stenlid, Jonas Oliva and Audrius Menkis \\ 1 Animal and Plant Health Inspection Service, United States Department of Agriculture, Linden, \\ NJ 07036, USA; greynolds@ucdavis.edu \\ 2 Department of Plant Pathology, University of California, Davis, CA 95616, USA; nmcroberts@ucdavis.edu \\ * Correspondence: trgordon@ucdavis.edu; Tel.: +530-754-9893
}

\begin{abstract}
Pitch canker, caused by Fusarium circinatum, is a disease affecting Monterey pine (Pinus radiata) and many other pine species throughout the world. The impact of pitch canker on Pinus radiata may be limited by systemic acquired resistance (SAR), a phenomenon that elevates resistance to a pathogen after initial challenge by that pathogen or another microorganism. Allocation of resources to defense, as a consequence of SAR, is presumed to reduce resources available to support growth and reproduction, but specific fitness consequences associated with SAR in P. radiata have not been measured. To quantify impacts of SAR on growth rate, a $2 \times 2$ factorial experiment was established in which trees were either primed for SAR or unprimed, with half the trees in each of those two groups being inoculated with the pitch canker pathogen and the other half not inoculated. Priming for SAR was accomplished by inoculating one branch with F. circinatum and removing inoculated branches prior to subsequent challenge inoculations (= disease treatments). Disease treatments included three inoculations that were removed for measurement of lesion length, and three additional inoculations that remained on the tree as a representation of persistent disease. Control trees were mock inoculated with water. Main effects of priming and disease did not result in significant effects on growth rate. Based on hyperspectral canopy reflectance data, diseased trees were associated with higher difference vegetation index values and biomass. The absence of a negative impact on growth rate associated with SAR suggests that induction of resistance may have utility as a tool for management of pitch canker in plantations.
\end{abstract}

Keywords: systemic acquired resistance; Pinus radiata; pitch canker

\section{Introduction}

Monterey pine (Pinus radiata D. Don) is a dominant tree species in native forests in coastal California. The range of $P$. radiata has shifted with climate change over time and currently is limited to three locations on the central coast of California and two islands off Baja California [1]. Pinus radiata is also grown on over 4.2 million hectares as a plantation species in Mediterranean climates, with major production areas in New Zealand, Australia, Spain and Chile [2]. Because P. radiata is so important to plantation forestry, native populations are a vital resource for maintaining genetic diversity in the species [3]. All native populations in California are currently affected by pitch canker, a disease caused by Fusarium circinatum (Nirenberg \& O'Donnell). Pitch canker was first described in the southeastern United States by Hepting and Roth [4], and was identified in California in 1986 [5], where it was associated with extensive mortality in planted stands of $P$. radiata. The pathogen appears to have been a recent introduction from the southeastern U.S., with limited diversity in the California population [6]. 
In California, branch and trunk infections are initiated primarily by various insect species that serve as vectors and wounding agents [6]. Infections can girdle branches and cone whorls, potentially reducing growth rate and fecundity, and trees may be killed if the main stem is compromised.

Systemic acquired resistance (SAR) is a mechanism that allows plants to respond to infections by activating metabolic responses that increase resistance to subsequent infection attempts [7]. The phenomenon is well documented in experimental studies with annual crop plants and model species, such as Arabidopsis thaliana [8]. In P. radiata, exposure to F. circinatum has been shown to induce SAR under controlled conditions [9]. Systemic acquired resistance in P. radiata also occurs under natural conditions [10], and may help to explain diminished severity of the pitch canker epidemic in California [11].

Although the occurrence of SAR in the pitch canker-P. radiata pathosystem has been well-documented, possible impacts of SAR on $P$. radiata fitness have not been investigated. Fitness costs associated with SAR have been identified in several other plant hosts, including both wheat [12] and Arabidopsis [13] chemically primed for resistance with acibenzolar-S-methyl (BION), and barley induced by an avirulent Erysiphe graminis isolate [14]. However, other studies have shown no impact of SAR on fitness [7]. Furthermore, some work has even demonstrated fitness benefits to induction of resistance, with increased growth rate in tobacco induced by Perenospora tabacina [15] and increased seed yield in Arabidopsis chemically induced with low rates of $\beta$-Aminobutyric acid (BABA) [16].

Our objective in this study was to quantify any impacts of SAR induced by F. circinatum on growth rate of $P$. radiata.

\section{Materials and Methods}

\subsection{Field Trials}

Two plantations were established using P. radiata control-pollinated seed-line GF-28 (PF Olsen Limited; Rotorua, New Zealand). Prior to planting, seeds were surface sterilized for $30 \mathrm{~s}$ in $70 \% \mathrm{EtOH}$ and $1 \mathrm{~min}$ in $1 \% \mathrm{NaClO}$, rinsed in sterile distilled water and soaked in sterile distilled water overnight at $4{ }^{\circ} \mathrm{C}$. Seeds were sown in Sunshine Mix Potting Soil (Sun Gro Horticulture; McClellan Park, CA, USA) and covered in $2 \mathrm{~cm}$ of sterile field sand that had been autoclaved twice for $1 \mathrm{~h}$ on consecutive days. Two seeds were sown in each container $(21 \times 2.8 \mathrm{~cm}, 164 \mathrm{~mL}$ Ray Leach Cone-tainers (Steuwe and Sons; Tangent, OR, USA)), with post-emergence thinning, as needed, to one seedling per pot. Seedlings were supplied as necessary with tap water and maintained for ten months in a greenhouse with temperatures ranging from 27 to $37^{\circ} \mathrm{C}$ before being transplanted to the field as two adjacent plantations in Davis, CA in November 2011 to be used as field trials for a repeated experiment (Figure 1). Each plantation was comprised of 160 treatment trees surrounded by a single row of border trees to minimize any edge effects. Soil type was Yolo silty clay loam. Trees were furrow-irrigated as needed. Weeds were controlled with tillage and hoeing.

The experiment was a $2 \times 2$ factorial design for a total of four treatments: priming for SAR vs. not priming and disease induced by F. circinatum vs. no disease. Treatments were arranged in a randomized complete block design with 10 trees per treatment in each of four blocks for a total of 40 trees per treatment per field trial. Priming for SAR was accomplished through inoculation of one branch on each tree with $5 \mu \mathrm{L}$ of a $5 \times 10^{4}$ spores $/ \mathrm{mL}$ suspension of $F$. circinatum. The spore suspension was deposited into a wound made using a $1.6 \mathrm{~mm}$ diameter drill bit to penetrate the bark. Priming inoculations occurred on 8 May 2013 in the first trial and on 20 October 2013 for the second trial (Figure 1). A longer post-priming incubation period was allowed for the second trial because lesions develop more slowly in cooler weather over the winter; duration of priming lesion development for each trial was normalized using a basic growing degree day model with $40^{\circ} \mathrm{F}$ as a minimum temperature for F. circinatum growth. Priming branches were removed at 63 or 133 days after inoculation for the first and second trials, respectively, and lesion lengths were measured. One week following priming branch removal, each tree in the "disease" treatment group was inoculated on three branches, as described above for priming 
inoculations. The first set of disease inoculations was administered on 16 September 2013 for the first trial and on 11 March 2014 for the second trial (Figure 1). The second set of disease inoculations was administered on 28 September 2013 for the first trial and on 3 June 2014 for the second trial (Figure 1). Control trees (unprimed and healthy (= non-inoculated) were treated in the same manner but with water substituted for the spore suspension.

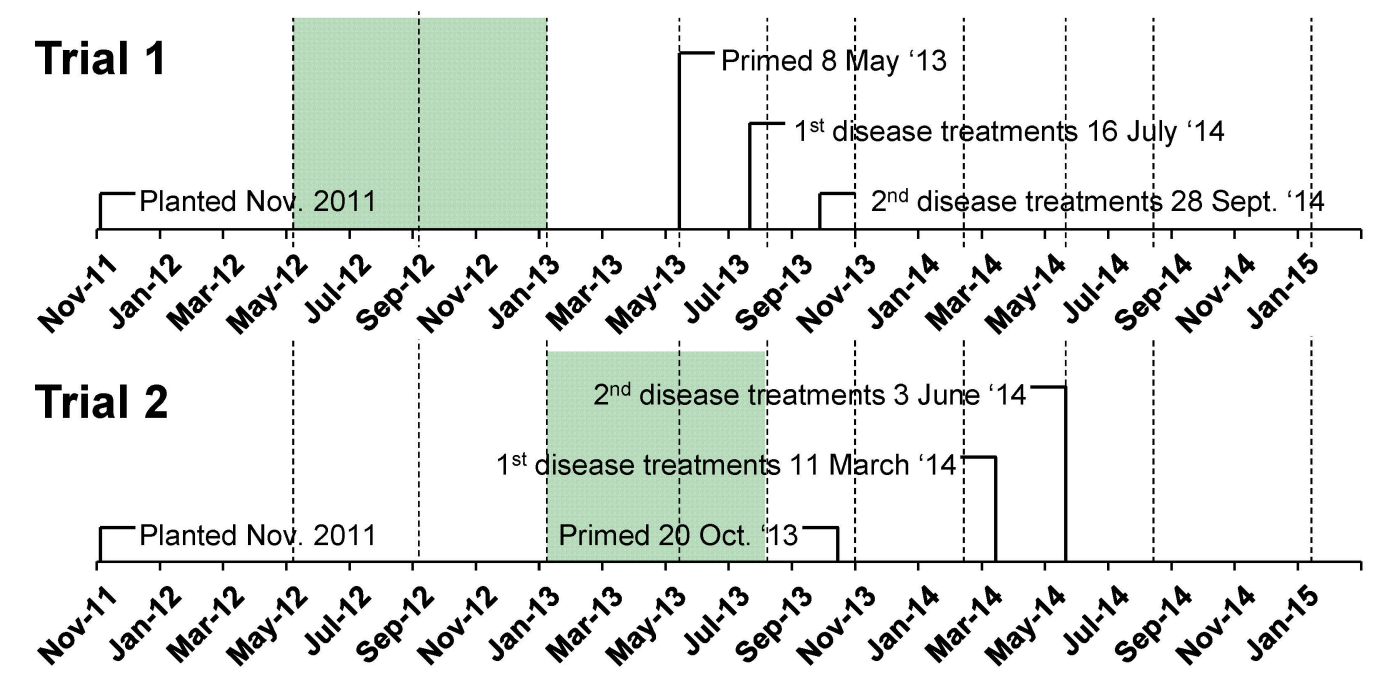

Figure 1. Timeline showing dates for application of priming and disease treatments (inoculation with Fusarium circinatum) to Pinus radiata in field trials. Dashed lines represent growth rate measurement dates. Shaded areas represent the baseline growth period measured prior to the application of treatments.

Isolations were made from a subset of 10 randomly selected branches per block from disease inoculations after the experiment was completed to confirm the presence of F. circinatum. Isolations were accomplished by taking tissue samples from lesion margins and submersing them for $30 \mathrm{~s}$ in $70 \%$ ethanol, followed by $1 \mathrm{~min}$ in $1 \% \mathrm{NaOCl}$. Thereafter, tissue samples were incubated on a Fusarium Selective Medium [17] for one to two weeks to visually confirm the presence of the pathogen based on morphological characteristics [18].

\subsection{Growth Rate Measurements}

Height and stem diameter were measured for each tree and stem volume was calculated from these data at five months after planting on 1 May 2012, and subsequent pre-treatment measurements for both trials were acquired on 28 August 2012 (120 day interval) and 4 January 2013 (130 day interval). These data were used to generate a baseline growth rate for all trees prior to application of treatments (= inoculations). Pre-treatment measurements were also obtained for the second trial on 15 May 2013 (132 day interval) and 8 August 2013 (86 day interval) to measure initial growth rate until just prior to inoculations (Figure 1). Measurement interval length varied because of weather, as rain prevented access to the field at various times.

Following priming inoculations, tree height and stem diameter were measured four times per year to provide an indication of treatment effects on growth rate (Figure 1). Heights were measured to the nearest centimeter using a $5 \mathrm{~m}$ measuring stick. Stem diameter was measured at approximately $10 \mathrm{~cm}$ above the soil line using a caliper when diameters were smaller than $80 \mathrm{~cm}$ and a diameter tape for larger trees. Stem volume was estimated by calculating the volume of a cone using measured values of stem height and radius. At each assessment date, growth was calculated as a percentage increase for the most recent interval and cumulatively after priming according to the following equation:

$$
R_{t}=100 \times\left(V_{t}-V_{t-1}\right) / V_{t-1}
$$


where $R_{t}$ is the percentage increase over a given period of time, $V_{t}$ is the volume at the current time, and $V_{t-1}$ is the volume at the previous time.

\subsection{Hyperspectral Reflectance Measurements}

Hyperspectral remote sensing was used to provide estimates of biomass and plant stress [19]. To this end, reflectance data measured from the canopy were acquired for a subset of trees using a FieldSpec FR hand-held spectroradiometer (Analytical Spectral Devices, Inc.; Boulder, CO, USA). The instrument houses three separate spectrometers in one enclosure and has sampling intervals of $1.4 \mathrm{~nm}$ for the 350- to 1000-nm region of the electromagnetic spectrum (3-nm spectral resolution) and $2 \mathrm{~nm}$ for the 1000- to $2500-\mathrm{nm}$ region (10-nm spectral resolution). The field of view was $25^{\circ}$, and measurements were obtained $10 \mathrm{~cm}$ above the tips of each tree at nadir. Dead inoculated branches were cut at the inoculation site and removed so that dead plant tissue would not influence measurements. Reflectance, therefore, represents only visibly healthy tissue and may provide insights into differences due to SAR; reflectance data were obtained after the last growth measurements so growth data would not be affected by branch removal. Thirty measurements were obtained per tree and averaged. Measurements were obtained on clear, sunny days between 10:00 A.M. and 2:00 P.M. PST to maintain consistent sun angle and intensity for all trees. The instrument was calibrated and optimized with a spectralon white reflectance panel every $5 \mathrm{~min}$ while readings were being obtained to maintain consistency for all measurements. The panel reflects close to $100 \%$ of incident radiation; reflectance values are calculated as a ratio of reflected radiation from the tree canopy to incident radiation. Spectral measurements were obtained for every tree in two out of four blocks for each field trial for a total of 160 .

\subsection{Statistical Analyses}

Lesion lengths in primed versus unprimed trees were compared using $t$-tests to confirm that induction of SAR was successful, using the R statistical programming language. Data were checked for normality visually using graphical displays of distributions, and homogeneity of variance was confirmed using $F$ tests. The effects of priming and disease on increases in stem volume were evaluated using analysis of variance (ANOVA) as implemented in Proc Mixed (SAS version 9.1), with priming, disease and the priming $\times$ disease interaction treated as fixed effects. Block (nested in replication), replication, and replication $\times$ treatment interaction terms were treated as random effects. The significance of random effects was evaluated using a chi-square test to compare residual log likelihood values obtained with and without the random term included in the model. Percentage data were arcsine-transformed prior to analysis.

Hyperspectral reflectance signatures were visually assessed using ViewSpecPro (Analytical Spectral Devices, Inc). Vegetation indices from spectral measurements were also calculated and analyzed using ANOVA in R. All indices assessed by Reynolds et al. [20] were tested in this experiment, but wideband indices were adapted into narrowband indices using $554 \mathrm{~nm}$ for green reflectance, $670 \mathrm{~nm}$ for red reflectance, and $775 \mathrm{~nm}$ for near-infrared reflectance.

\section{Results}

\subsection{Induction of $S A R$}

Histograms showing lesion length distributions from primed and unprimed trees confirmed induction of SAR as reduced lesion lengths in primed trees compared with unprimed trees (Figure 2). A $t$-test indicated that primed trees had significantly shorter lesion lengths on average than unprimed trees $(P<0.0001$ for both trials). In the first trial, lesion lengths averaged $63 \mathrm{~mm}$ in trees primed by inoculation with F. circinatum and $74 \mathrm{~mm}$ in trees that were not primed; in the second trial, lesion lengths averaged 78 and $86 \mathrm{~mm}$, in primed and unprimed trees, respectively. Fusarium circinatum was 
isolated from lesion margins on $100 \%$ of the branches that were sampled. No symptoms were observed on any branches that were not inoculated.

Trial 1

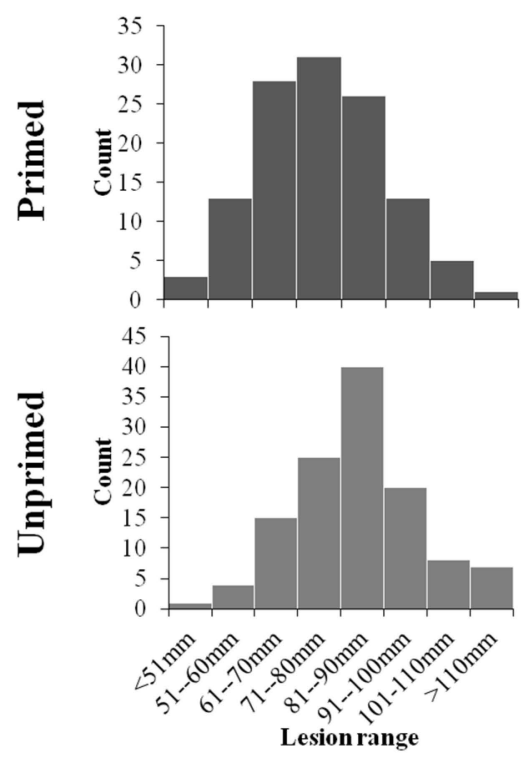

Trial 2

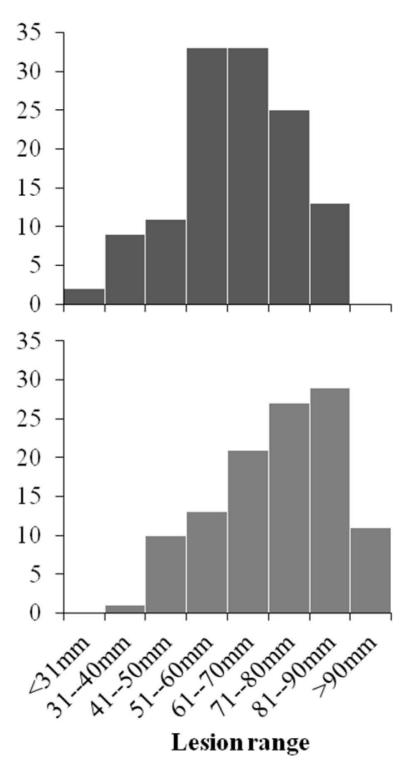

Figure 2. Distribution of lesion lengths resulting from inoculations of Pinus radiata with Fusarium circinatum. Three branches were inoculated on each of 160 trees, 80 in each of two repetitions of the experiment. In each experiment, 40 trees were primed and 40 were unprimed.

\subsection{Treatment Effects on Growth Rate}

Growth rates differed between the two plantings and trees in the second replication were larger than trees in the first replication of the experiment when priming treatments were applied (Table 1).

Table 1. Height and diameters of Pinus radiata when priming treatments were applied.

\begin{tabular}{ccccccc}
\hline \multirow{2}{*}{ Replication $^{1}$} & \multicolumn{3}{c}{ Height (cm) } & \multicolumn{3}{c}{ Diameter (mm) } \\
\cline { 2 - 7 } & Mean & Median & Range & Mean & Median & Range \\
\hline One & 111 & 112 & $46-168$ & 24 & 24 & $10-37$ \\
Two & 173 & 178 & $60-280$ & 37 & 37 & $10-61$ \\
\hline
\end{tabular}

${ }^{1}$ Two plantings that served as replications of the experiment.

This difference between replications continued following priming, and the effect of replication on increases in stem volume were significant at $3(P=0.0160), 6(P=0.0179)$ and 9 months $(P=0.0455)$ after priming, but not at 12 months $(P=0.0577)$. Differences in growth rate between experiments did not differentially affect treatments, as indicated by non-significant treatment $\times$ replication interactions at all measurement intervals; $P \geqslant 0.9999$ and $P \geqslant 0.7518$, for replication $\times$ priming and replication $\times$ disease interactions, respectively. With data pooled across both replications of the experiment, effects of priming and disease treatments on growth were not significant at any measurement interval (Table 2). Although main effects were not significant, the priming $\times$ disease interaction was significant at $3(P=0.0039), 6(P=0.0155)$ and 9 months $(P=0.0126)$, and nearly so at 12 months $(P=0.0551)$. The significance of the interaction reflects a greater impact of priming on diseased than on healthy trees (Figure 3). 
Table 2. Analysis of fixed effects on increases in stem volume of Pinus radiate.

\begin{tabular}{ccccc}
\hline Growth Interval $^{\mathbf{1}}$ & Factor $^{\mathbf{2}}$ & $\mathbf{D F}^{\mathbf{3}}$ & $\boldsymbol{F}$-Value & $\boldsymbol{P ( > \boldsymbol { F } ) ^ { \mathbf { 4 } }}$ \\
\hline Three months & Priming (P) & 1,312 & 0.50 & 0.6077 \\
Three months & Disease (D) & 1,312 & 0.38 & 0.6485 \\
Three months & $\mathrm{P}^{*} \mathrm{D}$ & 1,312 & 8.45 & 0.0039 \\
Six months & Priming (P) & 1,314 & 0.15 & 0.6975 \\
\hline Six months & Disease (D) & 1,314 & 0.71 & 0.3999 \\
Six months & $\mathrm{P}^{*} \mathrm{D}$ & 1,314 & 5.93 & 0.0155 \\
Nine months & Priming (P) & 1,314 & 1.44 & 0.2306 \\
Nine months & Disease (D) & 1,314 & 2.08 & 0.1503 \\
Nine months & P*D & 1,314 & 6.29 & 0.0126 \\
Twelve months & Priming (P) & 1,315 & 3.71 & 0.0551 \\
Twelve months & Disease (D) & 1,315 & 1.34 & 0.2477 \\
Twelve months & $\mathrm{P}^{*} \mathrm{D}$ & 1,315 & 3.60 & 0.0586 \\
\hline
\end{tabular}

${ }^{1}$ Number of months since application of treatments (branches primed or not); ${ }^{2}$ Priming: trees were either inoculated with F. circinatum (= primed) or not (= control); Disease: six branches on each tree were inoculated with F. circinatum (= diseased) or not (= control); $\mathrm{P}^{*} \mathrm{D}=$ interaction between priming and disease treatments; ${ }^{3}$ Degrees of freedom for numerator (first number) and denominator (second number); ${ }^{4}$ Probability of obtaining a larger $F$ value by chance.

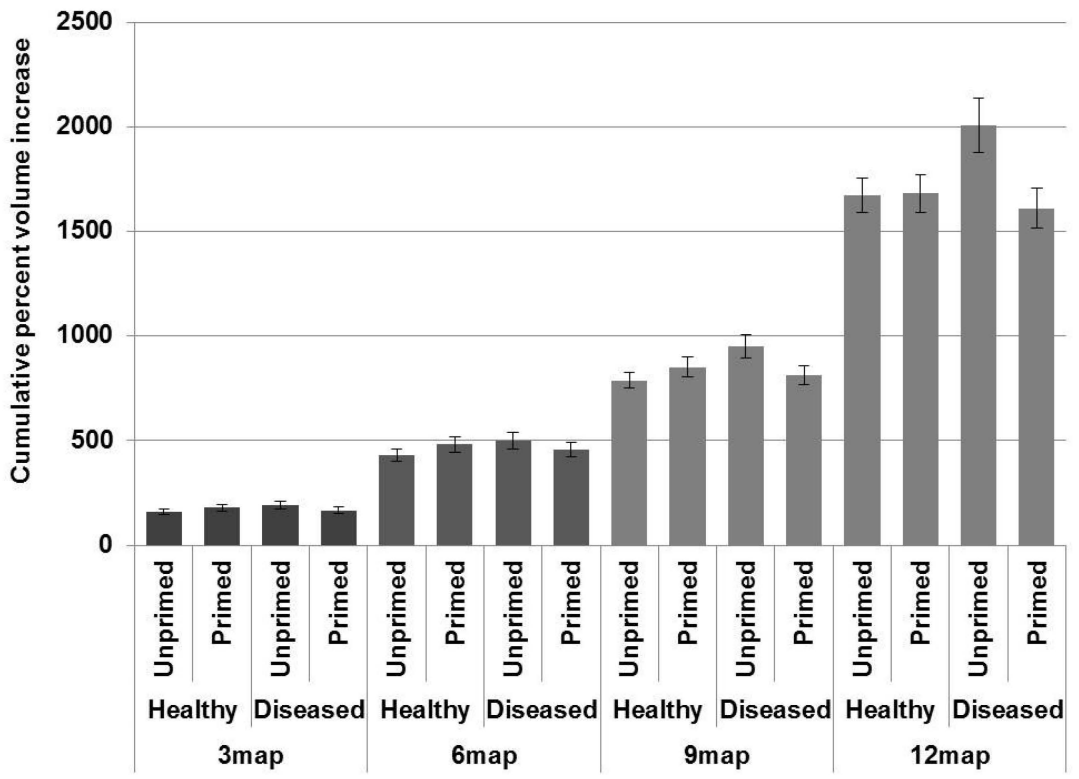

Figure 3. Cumulative percent stem volume increase in Pinus radiata either primed or unprimed for SAR and either healthy or diseased (inoculated with Fusarium circinatum) at 3, 6, 9 and 12 months after priming (map). Each bar represents an average of 80 trees from repeated field trials. Error bars denote the standard error of the mean.

\subsection{Spectral Measurements}

Higher near-infrared reflectance occurred in diseased trees than in healthy trees (Figure 4). There were no significant effects due to priming alone. In general, reflectance spectra were otherwise consistent between treatments. The effects of disease on difference vegetation index (DVI) and red-edge vegetation stress index (RVSI) were both statistically significant $(P<0.05)$. The DVI averaged 0.34 for healthy trees and 0.36 for diseased trees (Figure 5). The RVSI averaged -0.030 for healthy trees and -0.032 for diseased trees. The leaf water index (LWI) [21] averaged 5.6 for unprimed trees and 5.9 for primed trees, whereas the normalized difference vegetation index (NDVI) [22] averaged 0.85 in unprimed trees and 0.86 in primed trees. These differences were not significant at the $P=0.05$ level. 
Likewise there were not significant differences $(P>0.05)$ in the optimized soil adjusted vegetation index (OSAVI) [23], which averaged 0.061 in unprimed trees, 0.062 in primed trees, 0.061 in healthy trees and 0.062 in diseased trees.

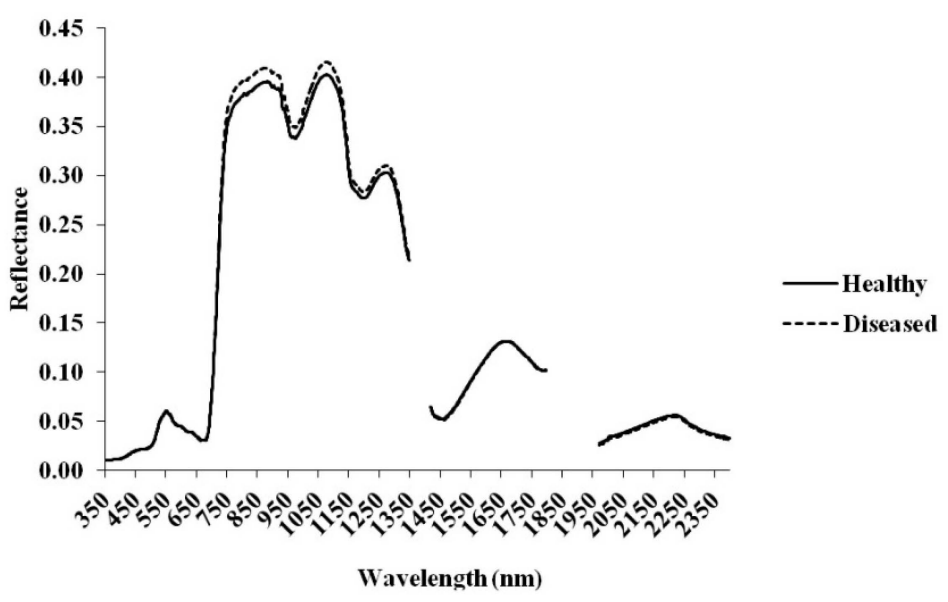

Figure 4. Average hyperspectral reflectance signatures obtained at nadir from the canopy of Pinus radiata either infected or uninfected by Fusarium circinatum. Diseased trees showed an increase in near-infrared reflectance between 750 and $1250 \mathrm{~nm}$, indicating that they were healthier than the disease-free trees.

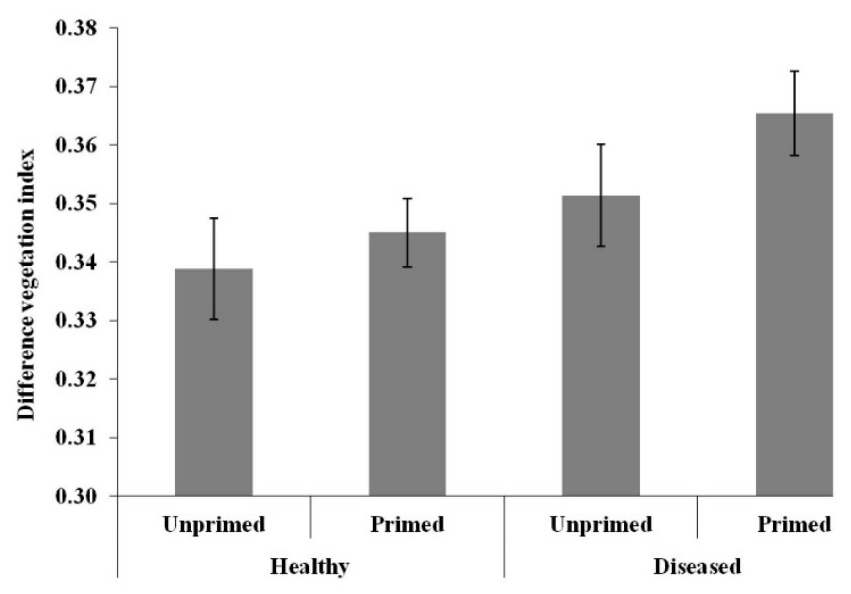

Figure 5. Difference vegetation index (DVI) values obtained from canopy-based hyperspectral reflectance measurements at nadir from Pinus radiata trees either primed or unprimed for systemic acquired resistance and healthy or diseased with pitch canker. Values for DVI were calculated as near-infrared reflectance $(775 \mathrm{~nm})$ minus red reflectance $(670 \mathrm{~nm})$ and are related to vegetation biomass. Similar differences were observed in related vegetation indices.

\section{Discussion}

Priming treatments resulted in reduced pitch canker lesion lengths compared to unprimed trees in both trials (Figure 2), which confirms the occurrence of SAR in primed trees. This is consistent with previous reports documenting induced resistance to pitch canker in $P$. radiata as a result of prior exposure to F. circinatum under controlled conditions [9], and field studies that provide evidence for the operation of SAR under natural conditions [10]. These findings suggest that SAR may provide a means by which populations can adapt to an exotic pathogen relatively quickly, allowing time for natural selection to enrich the population for individuals with higher levels of inherent genetic resistance. This scenario can help to explain the evolutionary success of long-lived perennials that have historical 
associations with parasites manifesting generation times that are orders of magnitude shorter than that of their host trees.

Against these benefits must be weighed a cost of SAR, which could result from allocation of resources to defensive compounds at the expense of growth and possibly also from inherent toxicity of those compounds [24]. Slower growth could heighten the risk of a tree being over-topped by faster growing con-specifics, reducing access to light and ultimately the capacity to produce seed. Previous work has shown that SAR may or may not be associated with reduced growth [12,25], whereas enhanced growth is also possible [15]. Most studies on SAR have involved annual plants [13] and thus do not provide information on long term effects of induced resistance. Our data showed no significant effect of induced resistance on growth of $P$. radiata during the first 12 months after trees were induced by inoculation with $F$. circinatum. Both priming and disease treatments consisted of inoculation with F. circinatum, so trees given the additional inoculations (= disease treatment) may be more strongly primed for SAR, and likewise more affected by any impact of SAR on growth. This, coupled with direct negative effects of disease, such as the loss of photosynthetic tissue, should make the primed + diseased trees most likely to suffer reductions in growth [26]. However, trees in this treatment group had growth rates that were nearly indistinguishable from those of healthy trees that were either primed or not (Figure 3). Thus under the conditions of our test, as many as seven branch infections did not have a significant impact on tree growth. This suggests that induction of resistance with a single inoculation carries little risk of reducing the rate of stem volume increase. Of course, we cannot preclude the possibility that an impact of SAR on growth might be detectable under other conditions and/or over a time period longer than 12 months.

Spectral differences between treatments were subtle if present, with diseased trees having slightly increased near-infrared reflectance (Figure 4), which typically indicates healthier vegetation [27]. The two vegetation indices that were statistically significant at the $P=0.05$ level, DVI and RVSI, reflect levels of biomass [28] and stress [3], respectively, and diseased trees showed both higher biomass (Figure 5) and lower levels of stress. Thus, although measures of stem volume did not reveal significant differences in growth rate, biomass accumulation may have been differentially affected by the disease treatment. That higher biomass would be found in diseased trees is counter to expectations and further work would be needed to confirm this effect. However, our findings are certainly consistent with the absence of a growth penalty associated with SAR.

The absence of an effect on growth in P. radiata suggests that SAR has potential as a disease management tool. Induced resistance to dieback caused by Diplodia has also been demonstrated in pines [29], indicating that SAR might contribute to management of multiple disease problems. For practical reasons, substituting a chemical inducer of resistance for inoculation with a pathogen would be desirable, and the findings reported by Reglinski et al. [30] and Fitza et al. [31] suggest that chitosan merits consideration in this regard.

\section{Conclusions}

Systemic acquired resistance induced by inoculation with $F$. circinatum does not incur a growth cost in P. radiata, and manipulation of SAR may thus be a valuable tool in plantation forestry disease management.

Acknowledgments: The authors thank the Pebble Beach Company, U.S. Forest Service and University of California-Davis, College of Agricultural and Environmental Sciences for funding this research. We also acknowledge Tom Kominek, Mike Eldridge and Bryan Pellisier for assistance with planting and maintaining Monterey pine plantations. We thank Susan Ustin, George Scheer, and Michael Whiting for providing equipment and advice for our remote sensing work. We also thank Annie Montes, Ashley Hawkins, Celeste Felix, Jenna Yoshisato, Emmi Koivunen, Steven Heisey, Kelley Paugh, James Whitney and Lola Quasebarth for helping with field work and data collection. The authors thank three anonymous reviewers for helpful comments.

Author Contributions: Greg Reynolds, Tom Gordon, and Neil McRoberts each contributed to experimental design, performing the experiments, data analysis and writing the manuscript.

Conflicts of Interest: The authors declare no conflict of interest. 


\section{References}

1. Jones and Stokes Associates. Final. Monterey Pine Forest Ecological Assessment: Historical Distribution, Ecology, and Current Status of Monterey Pine. Available online: http://www.co.monterey.ca.us/planning/major/ Pebble\%20Beach\%20Company /Pebble_Beach_DEIR_Nov_2011/Pebble_Beach_DEIR_Admin_Records_Nov_ 2011/Jones_Stokes/JS_1994_MPF_Eco_Assess.pdf (accessed on 4 January 2016).

2. Rogers, D.L.; Vargas Hernández, J.J.; Matheson, A.C.; Guerra Santos, J.J. The Mexican Island Populations of Pinus Radiata: An International Expedition and Ongoing Collaboration for Genetic Conservation. Available online: http://www.fao.org/docrep/005/y4341e/y4341e07.htm\#P947_91075/ (accessed on 4 January 2016).

3. Rogers, D.L. In situ genetic conservation of a naturally restricted and commercially widespread species, Pinus radiata. For. Ecol. Manag. 2004, 197, 311-322. [CrossRef]

4. Hepting, G.H.; Roth, E.R. Pitch canker, a new disease of some southern pines. J. For. 1946, 44, 724-744.

5. McCain, A.H.; Koehler, C.S.; Tjosvold, S.A. Pitch canker threatens California pines. Calif. Agric. 1987, 41, $22-23$.

6. Gordon, T.R.; Storer, A.J.; Wood, D.L. The pitch canker epidemic in California. Plant Dis. 2001, 85, 1128-1139. [CrossRef]

7. Walters, D.; Walsh, D.; Newton, A.; Lyon, G. Induced resistance for plant disease control: Maximizing the efficacy of resistance elicitors. Phytopathology 2005, 95, 1368-1373. [CrossRef] [PubMed]

8. Durrant, W.E.; Dong, X. Systemic acquired resistance. Annu. Rev. Phytopathol. 2004, 42, 185-209. [CrossRef] [PubMed]

9. Bonello, P.; Gordon, T.R.; Storer, A.J. Systemic induced resistance in Monterey pine. For. Pathol. 2001, 31, 99-106. [CrossRef]

10. Gordon, T.R.; Kirkpatrick, S.C.; Aegerter, B.J.; Fisher, A.J.; Storer, A.J.; Wood, D.L. Evidence for the occurrence of induced resistance to pitch canker, caused by Gibberella circinata (anamorph Fusarium circinatum), in populations of Pinus radiata. For. Pathol. 2011, 41, 227-232. [CrossRef]

11. Storer, A.J.; Wood, D.L.; Gordon, T.R. The epidemiology of pitch canker in California. For. Sci. 2002, 48, 694-700.

12. Heil, M.; Hilpert, A.; Kaiser, W.; Linsenmair, K.E. Reduced growth and seed set following chemical induction of pathogen defence: Does systemic acquired resistance (SAR) incur allocation costs? J. Ecol. 2000, 88, 645-654. [CrossRef]

13. Dietrich, R.; Ploss, K.; Heil, M. Growth responses and fitness costs after induction of pathogen resistance depend on environmental conditions. Plant Cell Environ. 2005, 28, 211-222. [CrossRef]

14. Smedegaard-Petersen, V.; Stølen, O. Effect of energy-requiring defense reactions on yield and grain quality in a powdery mildew-resistant barley cultivar. Phytopathology 1981, 71, 396-399. [CrossRef]

15. Tuzun, S.; Kuc, J. A modified technique for inducing systemic resistance to blue mold and increasing growth in tobacco. Phytopathology 1985, 75, 1127-1129. [CrossRef]

16. Van Hulten, M.; Pelser, M.; van Loon, L.C.; Pieterse, C.M.J.; Ton, J. Costs and benefits of priming for defense in Arabidopsis. Proc. Natl. Acad. Sci. USA 2006, 103, 5602-5607. [CrossRef] [PubMed]

17. Aegerter, B.J.; Gordon, T.R. Rates of pitch canker induced seedling mortality among Pinus radiata families varying in levels of genetic resistance to Gibberella circinata (anamorph Fusarium circinatum). For. Ecol. Manag. 2006, 235, 14-17. [CrossRef]

18. Leslie, J.F.; Summerell, B.A.; Bullock, S. The Fusarium Lab Manual; Blackwell: Ames, IA, USA, 2006.

19. Knipling, E.B. Physical and physiological basis for the reflectance of visible and near-infrared radiation from vegetation. Remote Sens. Environ. 1970, 1, 155-159. [CrossRef]

20. Reynolds, G.J.; Windels, C.E.; MacRae, I.V.; Laguette, S. Remote sensing for assessing Rhizoctonia crown and root rot severity in sugar beet. Plant Dis. 2012, 96, 497-505. [CrossRef]

21. Seelig, H.D.; Hoehn, A.; Stodieck, L.S.; Klaus, D.M.; Adams, W.W., III; Emery, W.K. Relations of remote sensing leaf water indices to leaf water thickness in cowpea, bean, and sugarbeet plants. Remote Sens. Environ. 2008, 112, 445-455. [CrossRef]

22. Rouse, J.W.; Haas, R.H.; Schell, J.A.; Deering, D.W. Monitoring vegetation systems in the Great Plains with ERTS. In Third Earth Resources Technology Satellite-1 Symposium; Stanley, C.F., Enrico, P.M., Margaret, A.B., Eds.; NASA: Washington, DC, USA, 1973; pp. 309-317.

23. Rondeaux, G.; Steven, M.; Baret, F. Optimization of soil-adjusted vegetation indices. Remote Sens. Environ. 1996, 55, 95-107. [CrossRef] 
24. Heil, M.; Baldwin, I.T. Fitness costs of induced resistance: Emerging experimental support for a slippery concept. Trends Plant Sci. 2002, 7, 61-67. [CrossRef]

25. Takatsuji, H. Development of disease-resistant rice using regulatory components of induced resistance. Front. Plant Sci. 2014, 5, 1-12. [CrossRef] [PubMed]

26. Bonello, P.; Gordon, T.R.; Herms, D.A.; Wood, D.L.; Erbilgin, N. Nature and ecological implications of pathogen-induced systemic resistance in conifers: A novel hypothesis. Physiol. Mol. Plant Pathol. 2006, 68, 95-104. [CrossRef]

27. Jordan, C.F. Derivation of leaf area index from quality of light on the forest floor. Ecology 1969, 50, $663-666$. [CrossRef]

28. Merton, R.N.; Harvey, L.E. Analysis of seasonal changes in Jasper Ridge vegetation biochemistry and biophysiology using multitemporal hyperspectral data. In Proceedings of the American Society for Photogrammetry and Remote Sensing (ASPRS) Annual Conference, Seattle, WA, USA, 7-10 April 1997.

29. Blodgett, J.T.; Eyles, A.; Bonello, P. Organ-dependant induction of systemic resistance and systemic susceptibility in Pinus nigra inoculated with Sphaeropsis sapinea and Diplodia scrobiculata. Tree Physiol. 2007, 27, 511-517. [CrossRef] [PubMed]

30. Reglinski, T.; Taylor, J.T.; Dick, M.A. Chitosan induces resistance to pitch canker in Pinus radiata. N. Z. J. For. Sci. 2004, 34, 49-58.

31. Fitza, K.N.E.; Payn, K.G.; Steenkamp, E.T.; Myburg, A.A.; Naidoo, S. Chitosan application improves resistance to Fusarium circinatum in Pinus radiata. S. Afr. J. Bot. 2013, 85, 70-78. [CrossRef]

(C) 2016 by the authors; licensee MDPI, Basel, Switzerland. This article is an open access article distributed under the terms and conditions of the Creative Commons by Attribution (CC-BY) license (http://creativecommons.org/licenses/by/4.0/). 